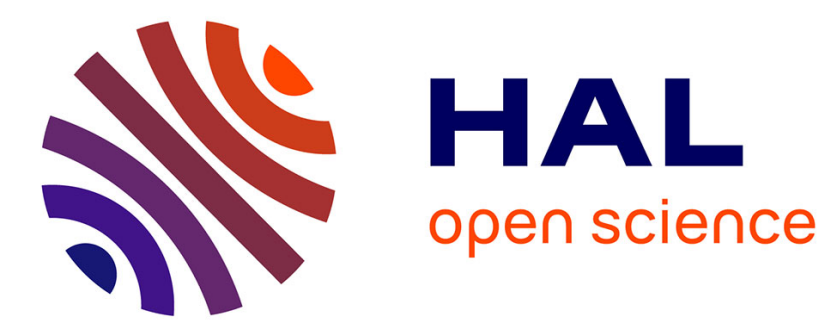

\title{
Thermal stability of Co/C multilayers
}

Jingtao Zhu, Yuchun Tu, Yanyan Yuan, Zhixiang Feng, Haochuan Li, Yizhi Zhang, Philippe Jonnard, Christian Mény, Karine Le Guen, Jean-Michel André, et al.

\section{- To cite this version:}

Jingtao Zhu, Yuchun Tu, Yanyan Yuan, Zhixiang Feng, Haochuan Li, et al.. Thermal stability of Co/C multilayers . Materials Research Express, 2014, 1, pp.046503. 10.1088/2053-1591/1/4/046503 . hal-01238002

\section{HAL Id: hal-01238002 https://hal.science/hal-01238002}

Submitted on 8 Dec 2015

HAL is a multi-disciplinary open access archive for the deposit and dissemination of scientific research documents, whether they are published or not. The documents may come from teaching and research institutions in France or abroad, or from public or private research centers.
L'archive ouverte pluridisciplinaire HAL, est destinée au dépôt et à la diffusion de documents scientifiques de niveau recherche, publiés ou non, émanant des établissements d'enseignement et de recherche français ou étrangers, des laboratoires publics ou privés. 


\title{
Thermal stability of $\mathrm{Co} / \mathrm{C}$ multilayers
}

\author{
Jingtao Zhu ${ }^{1 *}$, Yuchun Tu ${ }^{1,2,3}$, Yanyan Yuan ${ }^{2,3}$, Zhixiang Feng ${ }^{1}$, Haochuan Li ${ }^{1}$, Yizhi Zhang ${ }^{1}$,Philippe

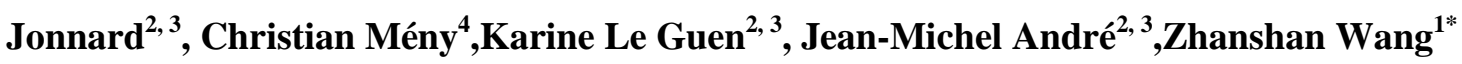 \\ 1 MOE Key Laboratory of Advanced Micro-structured Materials, School of Physics Science and Engineering, \\ Tongji University, Shanghai 200092, China \\ 2 Sorbonne Universités, UPMC Univ Paris 06, Laboratoire de Chimie Physique-Matière et Rayonnement, 11 \\ rue Pierre et Marie Curie, F-75231 France \\ 3 CNRS UMR 7614, Laboratoire de Chimie Physique-Matière et Rayonnement, 11 rue Pierre et Marie Curie, \\ F-75231, France \\ 4 Institut de Physique et Chimie des Matériaux de Strasbourg, UMR 7504 CNRS-Université De Strasbourg, 23 \\ rue du Loess, 67034 Strasbourg, France \\ memey \\ E-mail address : jtzhu@tongji.edu.cn and wangzs@tongji.edu.cn
}

\begin{abstract}
The structural and interface changes induced by thermal annealing in $\mathrm{Co} / \mathrm{C}$ multilayers were investigated. $\mathrm{Co} / \mathrm{C}$ multilayers with period thickness of $4.1 \mathrm{~nm}$ and bi-layer number of 20 were deposited by direct currentmagnetron sputtering.We characterized all samples by using X-ray reflectivity, X-ray diffuse scattering, zero-fieldnuclear magnetic resonancespectroscopy and X-ray diffraction. The results indicate that $\mathrm{Co}$ and $\mathrm{C}$ atoms mixed during deposition and then after annealing both atoms separated from their mixed region. The annealing process also causes asharpincrease of roughness at interfaces, which can be attributed to the crystallization of Co layers.
\end{abstract}

Keywords: Multilayer, X-ray optics, interface, thin film structure, NMR

\section{Introduction}

Multilayer mirrors are widely used as reflective optical elements for applications such as extreme ultraviolet (EUV) lithography [1], solar astrophysics imaging [2], synchrotron radiation [3] and x-ray spectrometry [4].Near the "carbon window" region $(\lambda \sim 4.5 \mathrm{~nm})$ where the absorption of carbon materials is low, Co/C multilayers have the rather hightheoretical reflectivity [5] and have been produced for Schwarzschild objective [6]. The peak reflectivity of $\mathrm{Co} / \mathrm{C}$ multilayers was measured to be $14.8 \%$ at incident angle of $5^{\circ}$.In $\mathrm{x}$-ray optics of synchrotron radiation beamlines and telescopes for astronomical observations, multilayers are used as monochromators and focusing elements. $\mathrm{Co} / \mathrm{C}$ multilayers are promising near $\mathrm{Co} \mathrm{K}$-edges because of their fine optical properties [7]. 
In order to improve the optical performance, it is necessary to deposit multilayer films that give rise to smooth and sharp interfaces, as the interface imperfections (i.e., roughness anddiffussion) will reduce the reflectance and increase non-specular scattering as well [7].Furthermore, multilayer mirrors are usually exposed to high flux of incident photons or endure high heat loads in practical applications such as solar observation or synchrotron radiation, where they might reach temperatures and heat load in excess of $500^{\circ} \mathrm{C}[8]$ and 100 $\mathrm{W} / \mathrm{mm}^{2}[9]$. It is known that the structure and interfaces of multilayers may change, e.g. period expansion or contraction, interdiffusion, crystallization, which could reduce the optical performance and accelerate the aging of the multilayer [10]. Thus, it is important to investigate the thermal stability andstructure evolution of the multilayers.

In this paper, we combinedX-ray reflectivity (XRR), X-ray diffuse scattering(XDS), zero-field nuclear magnetic resonance (NMR) spectroscopy and X-ray diffraction (XRD)techniques to investigate the evolution of structure and interfacesof $\mathrm{Co} / \mathrm{C}$ multilayers upon annealing.

\section{Experiments}

The $\mathrm{Co} / \mathrm{C}$ multilayers were deposited onto polished $\mathrm{Si}$ wafer by ultra-high vacuum direct current (DC) magnetron sputtering system with targets of Co (purity 99.95\%), C (purity 99.99\%). The working gas is argon (99.999\%). The base pressure was $1 \times 10^{-4} \mathrm{~Pa}$ and the sputtering gas pressure was $0.13 \mathrm{~Pa}$. The deposited multilayer was designed with bilayer number $\mathrm{N}=20$, period thickness $\Lambda=4.1 \mathrm{~nm}$, and the thickness of Co layer, $\mathrm{d}_{\mathrm{Co}_{0}}=1.5 \mathrm{~nm}$. The layer thickness was calibrated by using grazing incident $\mathrm{X}$-ray reflectivity measurement. After deposition, the samples were mounted on a plate heated by a wire-wound furnace in a vacuum chamber with a base pressure of $3 \times 10^{-4} \mathrm{~Pa}$. The samples were heated from room temperature to 300 and $600^{\circ} \mathrm{Ckeeping}$ for 1 hour. A detailed description of the deposition and annealing setup can be found in Ref. [11].

The structure of the multilayers was analyzed by using grazing incident XRR on aX-ray diffractometer (D1 system, Bede Inc.) at $\mathrm{Cu} \mathrm{K} \alpha$ line $(0.154 \mathrm{~nm})$ working in the $\theta-2 \theta$ mode. The angular resolution is $5 / 1000^{\circ}$. Bragg law corrected for refraction was used to determine the multilayer period. The fitting of the XRR curves performed with Bede Refs software was used to determine thickness, roughness and density of each layer.Rocking curves were measured by using the samediffractometerwiththe detector fixed at the angle of first order Bragg peak.XRD measurements in the symmetric $(\theta-2 \theta)$ geometry were performed on a Rigaku-Dmax-2550V powder diffractometer.

In order to probe the chemical state of the Co atoms within the multilayer, the samples are analyzed byNMR spectroscopy. The NMR spectra represent the distribution of the Co atoms as a function of their resonance 
frequency, i.e. the hyperfine field experienced by the Co nuclei [12-13]. The NMR resonance frequency is sensitive to the local environment of the probed atoms: nearest neighbor local structure and/or local chemical environment. To enhance the sensitivity, the testing temperature is $2 \mathrm{Kfor}$ all the samples.All spectra have been recorded for different values of radio frequency field strengths allowing for correcting the NMR intensities for a frequency dependent enhancement factor.

\section{Results and discussion}

\subsection{Grazing incident X-ray reflectivity}

Thegrazing incident $\mathrm{X}$-ray reflectivity curves of the $\mathrm{Co} / \mathrm{C}$ multilayers are presented inFigure 1.All the XRR curves were fitted to obtain the roughness, thickness and density of individual layers. The fitted values are listed in Table.1. For the sample annealed at $300^{\circ} \mathrm{C}$, the Bragg peaks slightlyshift to lower grazing incident angle with respect to those of as-deposited sample.This means a slightincrease of period thickness. When the sample was annealed at $600^{\circ} \mathrm{C}$, we observe anexpansion of $17.5 \%$ in period thickness (from $4.09 \mathrm{~nm}$ to $4.81 \mathrm{~nm}$ ).

The fitting results reveal that the carbon layer plays a crucial role in the period expansion. After $600^{\circ} \mathrm{C}$ annealing, the thickness of $\mathrm{C}$ layer increases from $2.58 \mathrm{~nm}$ to $3.37 \mathrm{~nm}$.Observation of period expansion in carbon-based multilayersafter annealingwasreported in $\mathrm{Cr} / \mathrm{C}$ [14],Pt/C [15] and W/C [16] systems. This phenomenon is attributed to the graphitization of the amorphous carbon layers by annealing, which is confirmed by Raman scattering measurements $[14,16]$. There is a convention of sp3 bond to sp2 bond and amorphous carbon structure to nanocrystalline graphite in carbon layers during annealing [14]. The density of carbon changes linearly with $\mathrm{sp}^{3}$ fraction [17]. That is to say, the density of carbon should decrease and the thickness of the carbon layers should increase upon annealing. The thickness of Co layers decrease from $1.51 \mathrm{~nm}$ to $1.44 \mathrm{~nm}$. This may be due to the demixing of $\mathrm{Co}$ and $\mathrm{C}$ atoms in the Co layers after annealing which will be mentioned below. 


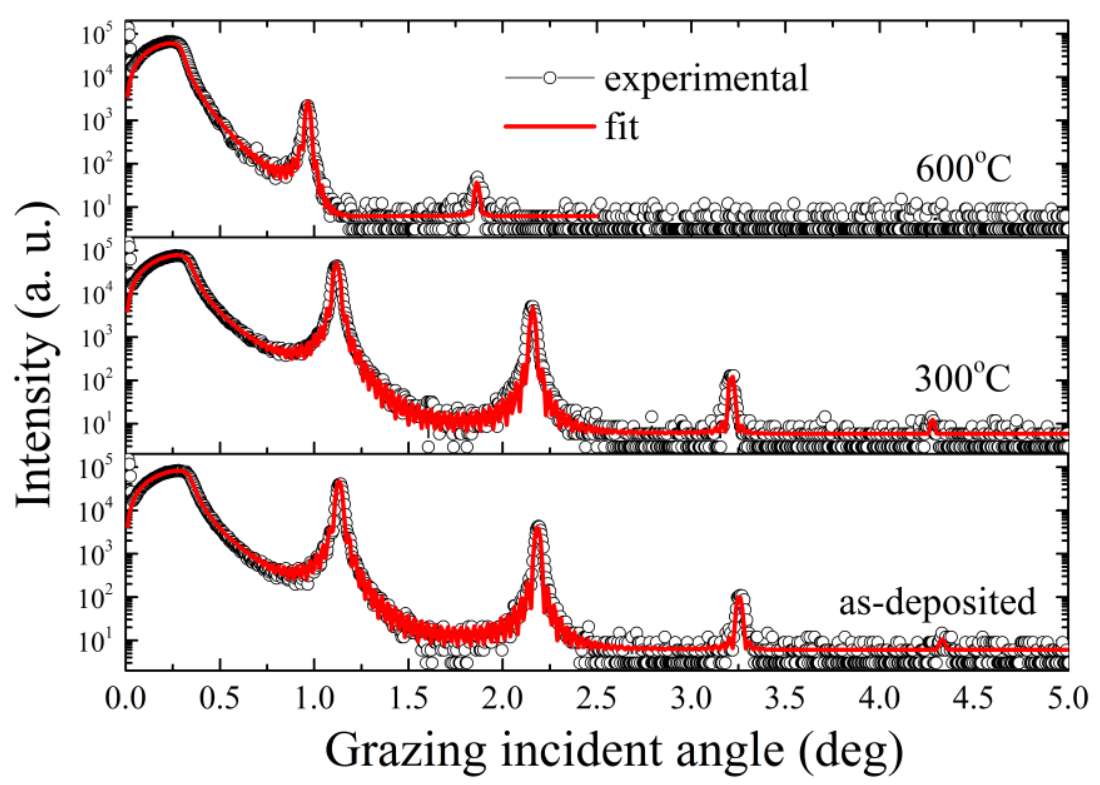

Fig. 1. Measured (black circle)and fitted (red solid line) XRR curves of as-deposited and annealed。Co/C multilayers.

Table.1. Parameters of the $\mathrm{Co} / \mathrm{C}$ multilayers deduced from fitting of the XRR curves.(The density ratio is the fitted density divided by the density of the bulk.)

\begin{tabular}{ccccccc}
\hline Sample & Period $\Lambda(\mathrm{nm})$ & $\mathrm{d}_{\mathrm{Co}}(\mathrm{nm})$ & $\mathrm{d}_{\mathrm{C}}(\mathrm{nm})$ & $\sigma_{\mathrm{Co}}(\mathrm{nm})$ & $\sigma_{\mathrm{C}}(\mathrm{nm})$ & Density ratio: Co $(\%), \mathrm{C}(\%)$ \\
\hline as-deposited & 4.09 & 1.51 & 2.58 & 0.41 & 0.37 & $89 \pm 5,93 \pm 5$ \\
$300^{\circ} \mathrm{C}$ annealing & 4.14 & 1.53 & 2.61 & 0.40 & 0.35 & $91 \pm 5,90 \pm 5$ \\
$600^{\circ} \mathrm{C}$ annealing & 4.81 & 1.44 & 3.37 & 1.16 & 1.02 & $98 \pm 5,80 \pm 5$ \\
\hline
\end{tabular}

In Figure 1, three well-defined peaks are observed for the as-deposited and $300^{\circ} \mathrm{C}$ annealed samples up to $3.5^{\circ}$.In the case of the $600^{\circ} \mathrm{C}$ annealed sample, only first and second Bragg peaks are observed and the reflectance decreased.The intensity of Bragg peaks increases slightly after $300^{\circ} \mathrm{C}$, meaning that there is aninterface smoothening effect in $\mathrm{Co} / \mathrm{C}$ multilayers. The comparison of the reflectivity curves shows that after $600^{\circ} \mathrm{C}$ annealing, the roughness of interfaces increases dramatically, from $0.4 \mathrm{~nm}$ to about $1.0 \mathrm{~nm}$. The roughness deduced from the fitting of XRR $(\sigma)$ is an overall imperfection of interfaces, including the contributions from both geometrical roughness $\left(\sigma_{\mathrm{r}}\right)$ and interdiffusion $\left(\sigma_{\mathrm{d}}\right)$. Possible reasons for thermally induced roughness change in $\mathrm{Co} / \mathrm{C}$ multilayers are investigated in the following.

\subsection{Zero-field nuclear magnetic resonance (NMR) spectroscopy}

NMR spectra for the Co/C multilayers are presented in Figure 2. All spectra in Fig.2 (a) are normalized to the surface area of each sample because the intensity is proportional to the size of samples. The spectrum of the 
$\mathrm{Co} / \mathrm{C}$ as-deposited multilayer shows a weak signal without any defined feature in the frequency range of pure Co.This indicates that the Co layers are not pure but that alien carbon atoms are mixed with Co over the total Co thickness. The as-deposited multilayers are actually $\mathrm{CoC}_{\mathrm{x}} / \mathrm{C}$ multilayer with probably some concentration gradient at the interface with the $\mathrm{C}$ layers. In addition some Co atoms are most probably also situated in non-ferromagnetic phases (and therefore give no NMR signal) with a large content of C.The metal-containing layer is a Co-C alloy with the density of $6.2-6.5 \mathrm{~g} / \mathrm{cm}^{3}$ that is less than density of massive Co and carbon enriched $\mathrm{Co}_{2} \mathrm{C}$ layers [18]. As a result, $\mathrm{Co} / \mathrm{C}$ multilayer mirrors consist of cobalt-carbon alloy and amorphous carbon layers.

The NMR spectrum of the $\mathrm{Co} / \mathrm{C} 300^{\circ} \mathrm{C}$ annealed sample shows no defined peak either, meaning that $\mathrm{Co}$ and Catoms are still stronglymixed in $\mathrm{CoC}_{\mathrm{x}}$ layers. There is a broad structureat $110 \mathrm{MHz}$ showing that some atomic motion occurred during annealing but the exact origin of this signal is difficult to identify. However,compared to the result of as-deposited samples, $\mathrm{Co}$ and $\mathrm{C}$ has a tendency of demixing at a temperature of $300^{\circ} \mathrm{C}$. Indeed the demixing processbetween the $\mathrm{Co}$ and $\mathrm{C}$ atoms increases thex-rayopticalcontrastof the $\mathrm{Co} / \mathrm{Cmultilayers}$. That is why the X-ray reflectivity is improved at temperature of $300^{\circ} \mathrm{C}$.

The spectrum of the $\mathrm{Co} / \mathrm{C} 600^{\circ} \mathrm{C}$ annealed sample shows a well-defined peak at about $220 \mathrm{MHz}$ which corresponds to bulk $h c p / f c c l i k e C o[12,13]$. This means that the pure Co regions appear and the diffusion decreasesat the interfaces. We infer from these results that $\mathrm{Co}$ and $\mathrm{C}$ layers in the $\mathrm{Co} / \mathrm{C}$ stack are strongly mixed during deposition and then demixingoccursupon annealing.

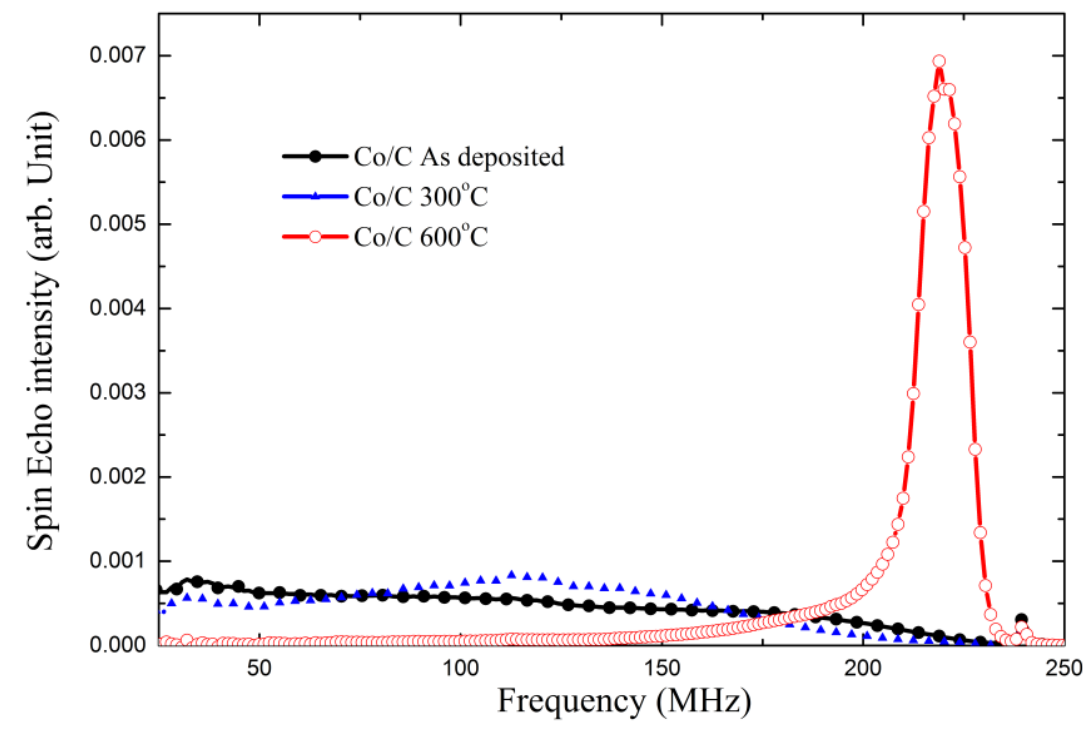

Fig. 2.Zero-field NMR spectra of as-deposited and annealed Co/C multilayers.

Based on the Miedema's macroscopic atom model [19], the mixing enthalpy of Co-C system is calculated and 
the results are shown in Fig.3. It can be seen that the value of mixing enthalpy is positive at any carbon concentration. Thisindicates that the Co-C system is easy to separate into two phases from the view of thermodynamics. This is in agreement with the NMR results. On the other hand, the carbon atoms separating out from $\mathrm{CoC}_{\mathrm{x}}$ layers may be an additional reason for the expansion of carbon layers.

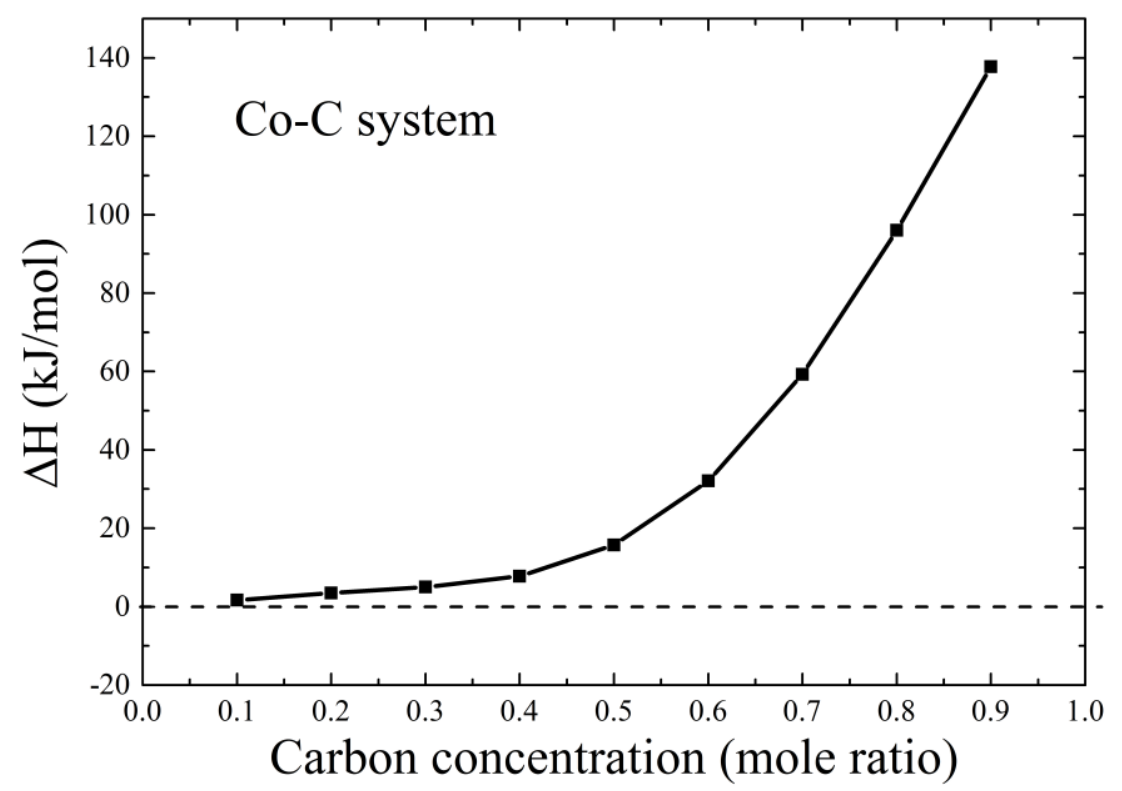

Fig.3.Theoretical calculated mixing enthalpy of the Co-C system.

\subsection{X-ray diffuse scattering}

The NMR results confirm the decrease of intermixing after annealing. Thus we attribute the deterioration of the interfaces to the increase of geometrical roughness. Therefore, X-ray diffuse scattering measurement was performed. Figure 4 shows the rocking curves measuredaround the first Bragg peakfor the three samples. For the as-deposited and $300^{\circ} \mathrm{C}$ annealed sample there is no significant change of the intensity except a slight shift of peak position.After annealed at $600^{\circ} \mathrm{C}$, a high intensity of diffuse scattered x-rays is observed, indicatingsignificant increase of the interfaces roughness. 


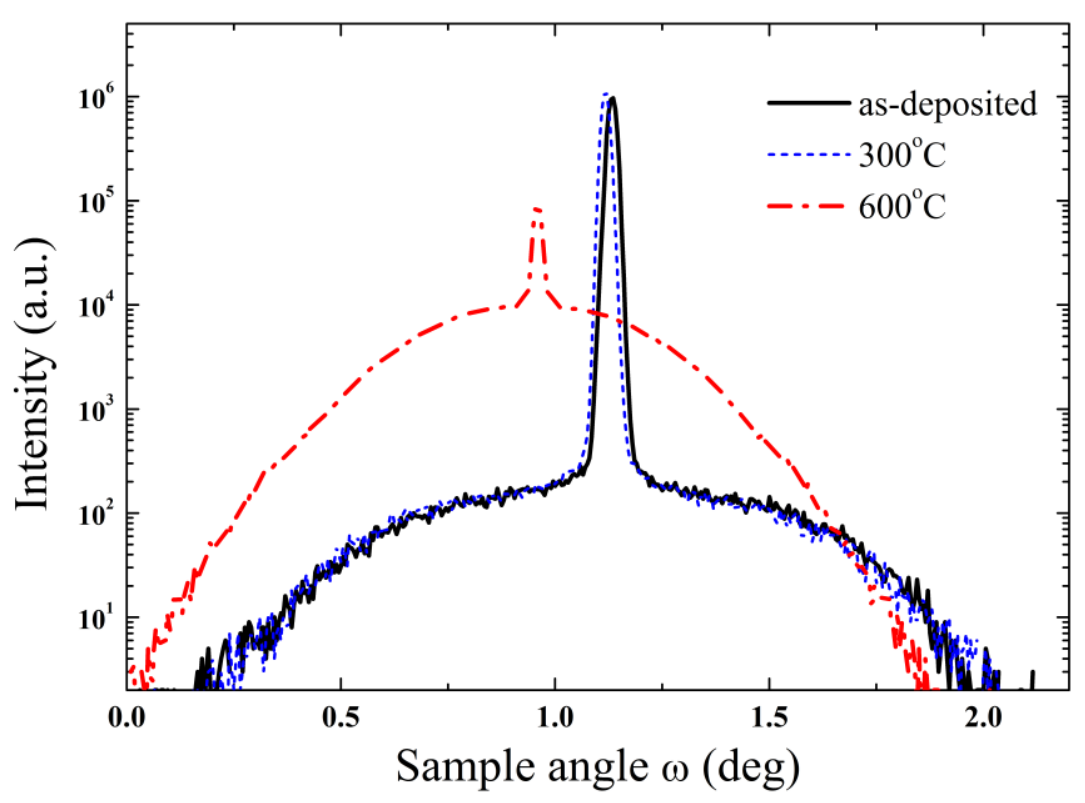

Fig.4. Rocking curves around the first Bragg peak of as-deposited and annealed Co/C multilayers.

\subsection{X-ray diffraction}

The $\mathrm{x}$-ray diffraction patterns of $\mathrm{Co} / \mathrm{C}$ as-deposited and annealed at $300^{\circ} \mathrm{C}$ and $600^{\circ} \mathrm{C}$ samples are presented in Fig.5. A broad intensity can be observed around $44.5^{\circ}$ around the $h c p(0002) / f c c$ (111) [20] peak position for the sample annealed at $600^{\circ} \mathrm{C}$. Compared with the amorphous layers of as-deposited and $300^{\circ} \mathrm{C}$ annealed sample, this peak indicatesa significant structural change:the amount of pure Co increases upon annealing. This is in good agreement with results of NMR spectra. Co and C atoms may not separate completely because the XRD peak is weak and its width is much broader than reported for $\mathrm{Co} / \mathrm{Cu}$ multilayers with $1.5 \mathrm{~nm}$ thick Co layers [21]. That is to say, the Co layers still contain a certain amount of $\mathrm{C}$ upon $600^{\circ} \mathrm{C}$ annealing.

The reduction in reflectivity induced by interface roughness becomes more significant as the multilayer period thickness decreases, because the ratio of the interface roughness to the multilayer period thickness directly affects the reflectivity according to the Debye-Waller factor [22]. Crystallization of metal layers in multilayers can cause an increase of geometrical roughness [23]. Crystallites can nucleate at some points during annealing. They have a size limited to the metal layer thicknessin the growth direction and arealso small in the in-plane direction. The spatial distribution of crystallites in the metal layer is replicated as a modulation of the surface height.Since the metal layer become rougher, the nonmetal layer on top of the metal layer also becomes rougher. For the $\mathrm{Co} / \mathrm{C}$ multilayers annealed up to $600^{\circ} \mathrm{C}$, the crystallization of Co layers increases the geometrical roughness and aggravates the overall imperfection of the interfaces. 


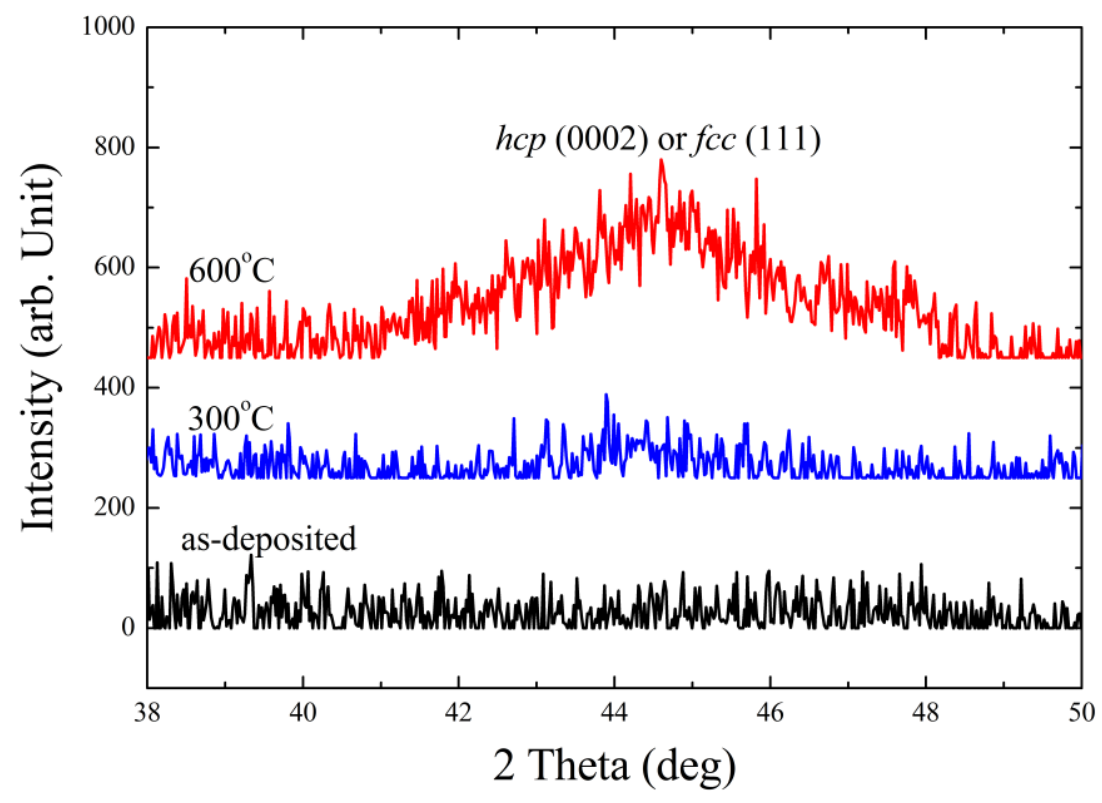

Fig.5.Diffraction patterns of as-deposited and annealed Co/C multilayers. The curveswere shifted vertically forthe sake of clarity.

\section{Conclusion}

Sputter-deposited $\mathrm{Co} / \mathrm{C}$ multilayers annealed up to $600^{\circ} \mathrm{C}(2.6 \mathrm{~nm} \mathrm{C} / 1.5 \mathrm{~nm} \mathrm{Co})_{20}$ areinvestigatedby using XRR, XRD, XDS and NMR techniques. The multilayer is stable up to $300^{\circ} \mathrm{C}$ and there isa slightincrease in the period and reflectivity.We demonstrate through the NMR spectroscopy that the strong demixingbetween Co and $\mathrm{C}$ atoms occursafter annealing at $600^{\circ} \mathrm{C}$.This phenomenon is also demonstrated by the Miedema'smodel which shows the phase separation of the Co-C system.The XDS and XRD results show that when the annealing temperature increases up to $600^{\circ} \mathrm{C}$, although the demixingof $\mathrm{Co}$ and $\mathrm{C}$ atoms increases thex-rayopticalcontrastof the $\mathrm{Co} / \mathrm{Cmultilayers,} \mathrm{the} \mathrm{formation} \mathrm{of} \mathrm{small} \mathrm{Co} \mathrm{crystallinegraincauses} \mathrm{the} \mathrm{interfaces}$ rough. The demixing and graphitization of the amorphous carbon layersinduceanexpansionof period thickness.

\section{Acknowledgement:}

This work was supported by CaiYuanpei Project (PHC No 30248NF), National Basic Research Program of China (No.2011CB922203), and National Natural Science Foundation of China (Nos. 11375131 and 11305104).

\section{References}

[1] D .L. Windt and W .K. Waskiewicz1994 J.Vac.Sci.Technol.B, 12 3826-3832

[2] J. F. Seely, C. M. Brown, D. L. Windt, S. Donguy, B. Kjornrattanawanich2004 App.Opt. 43 1463-1471

[3] C. Morawe, J-C. Peffen, E. Ziegler, A. K Freund 2001 Proc.SPIE $450161-71$ 
[4] C. Hombourger, P. Jonnard, J.-M. André, J. P. Chauvineau1999 X-Ray Spectrom. 28163-167

[5] H. Takenaka, K. Nagai, H. Ito, Y. Muramatsu, T. Kawamurac, E. Gullikson, R.C.C. Perera2001 Nucl. Instrum. Methods Phys. Res. A 467-468 337-340

[6] I.Artyukov, Y. Bugayev, O. Devizenko, E. Gullikson, V.Kondratenko, and A. Vinogradov2009Opt.Lett. 34(19) 2930-2932

[7] J. A. Bellotti and D. L. Windt2009 Proc. SPIE 743715, 1-7

[8] E. Ziegler, Y. Lepetre, I. K. Schuller, E. Spiller1986 Appl.Phys.Lett. 48 1354-1356

[9] J. A. Trail and R. L. Byer 1989 Opt. Lett. 14 539-541

[10]T. Bottger, D. C. Meyer, P. Paufler, S. Braun, M. Moss, H. Mai, E. Beyer 2003 Thin Solid Films 444 $165-173$

[11]J. Zhu, S. Zhou, H. Li, Q. Huang, Z. Wang, K. Le Guen, M.-H. Hu, J.-M. André, and P. Jonnard 2010 Appl. Opt. 49 3922-3925

[12] P. Panissod and C. Mény2000 Appl. Magn. Reson. 19 447-460

[13] M. Malinowska, C. Meny, E. Jedryka, P. Panissod1998 J Phys-Condens. Mat. 104919-4928

[14] Y. Tu, J. Zhu, H. Li, P. Jonnard, K. Le Guen, J-M. André, H. Chen, Z. Wang2014 Appl. Surf. Sci. 313 $341-345$

[15] G. S. Lodha, S. Pandita, A. Gupta, R. V. Nandedkar, K. Yamashita1996 Appl.Phys.A 62 29-32

[16] Z. Jiang, B. Vidal, G. Desrousseaux, V. Dupuis, M. Piecuch 1993 J.Appl.Phys.74 249-254

[17] A. C. Ferrari, J. Robertson, 2000 Phys. Rev. B 61(20) 14 095-107

[18] I. A. Artyukov et al 2005 Proc. SPIE 5919,59190E

[19]N. Das et al 2013 J. Alloys Compd. $550483-495$

[20] The diffraction information for Co is obtained from ICDD-PDF No.05-2727 and No.15-0806

[21] Kubota, H., S. Ishio, T. Miyazaki, and Z. M. Stadnik 1994 J. Magn. Magn. Mater. 129(2) 383-388

[22]D. K. G. De Boer, A. J. G. Leenaers, and W. W. Van den Hoogenhof1994 Appl.Phys.A 58 169-172

[23] S. Bajt, D. G. Stearns, P. A. Kearney 2001 J.Appl.Phys.90(2) 1017-1025 